\title{
Using the Person-Based Approach to develop a tailored intervention to prevent bacterial skin and soft tissue infections among people who inject drugs: A participatory study
}

\author{
Harriet Fisher ( $\sim$ Harriet.Fisher@bristol.ac.uk ) \\ NIHR Health Protection Research Unit in Behavioural Science and Evaluation \\ Jo Kesten \\ Weston NHS Foundation Trust \\ Deborah Hussey \\ Bristol Drugs Project \\ Catherine Lord \\ Bristol Drugs Project \\ Leonie Roberts \\ Bristol City Council \\ James Bayliss \\ Bristol, North Somerset \& South Gloucestershire Clinical Commissioning Group \\ Helen Erswell \\ UK Health Security Agency (UKHSA), South West Region \\ Andrew Preston \\ Exchange Supplies \\ Maggie Telfer \\ Bristol Drugs Project \\ Jenny Scott \\ University of Bath \\ Magdalena Harris \\ London School of Hygiene \& Tropical Medicine \\ Dominic Mellon \\ UK Health Security Agency (UKHSA), South West Region \\ Matthew Hickman \\ NIHR Health Protection Research Unit in Behavioural Science and Evaluation \\ Georgie MacArthur \\ University of Bristol
}

The National Institute for Health Research Applied Research Collaboration West (NIHR ARC West) at University Hospitals Bristol and

\section{Research Article}

Keywords: People who inject drugs, Skin and soft tissue infections, Person-based approach, Intervention development, Harm reduction, Behaviour change

Posted Date: February 24th, 2022

DOI: https://doi.org/10.21203/rs.3.rs-1336452/v1

License: (c) (1) This work is licensed under a Creative Commons Attribution 4.0 International License. Read Full License 


\section{Abstract}

Background: People who inject drugs (PWID) are at greater risk of developing bacterial skin and soft tissue infections (SSTI) than the general population. UK prevention interventions have achieved limited impact on the rising prevalence of SSTI among PWID. Innovative harm reduction interventions are needed. We present our approach to the co-development of a personalised, behavioural intervention, REACT (REducing bACTerial infections), which aims to prevent bacterial SSTI among PWID.

Methods: We followed the interrelated steps of the Person-Based Approach for intervention planning and development: (i) collating evidence, including published literature and consultations with PWID ( $n=15)$, service providers $(n=6)$, and stakeholders ( $n=11)$; (ii) developing guiding principles; (iii) undertaking a behavioural analysis; (iv) developing a logic model, and; (v) designing and refining intervention materials.

Results: Published literature highlighted structural barriers to safer injecting practices, such as access to hygienic injecting environments, homelessness and social exclusion. Practices associated with bacterial SSTI included: (i) handwashing / injection-site swabbing; (ii) overuse of acidifier; (iii) use of non-sterile water for injection preparation; (iv) reuse of injecting equipment; and; (v) lack of injecting site rotation. Consultations indicated vein care and minimisation of pain as priorities, while emphasising the importance of service provider-client relationships during intervention delivery. The need to deliver REACT in a non-judgemental and nonstigmatising manner, and to address stigma among PWID when communicating intervention messages, were additional priorities. Providing practical, tailored resources was identified as important to address environmental constraints to safer injecting practices. Findings were used to iteratively refine the REACT intervention.

Conclusion: Our evidence-based, collaborative and iterative approach, enabled alignment of the aim of the behavioural intervention to priorities of PWID, ensuring an appealing and acceptable intervention design while maximising likely feasibility of delivery and behaviour change. Piloting will establish the feasibility and acceptability of REACT to service providers and PWID.

\section{Background}

People who inject drugs (PWID) experience a range of health and social harms, including risk of overdose, blood-borne virus infection and the impacts of stigma and social and economic marginalisation, which lead to high levels of morbidity and premature mortality [1]. In addition, invasive bacterial skin and soft tissue infections (SSTI), such as Staphylococcus aureus and invasive Group A Streptococci (iGAS) are common among PWID. These can cause cellulitis, abscesses, ulcers and serious consequences including endocarditis, septic arthritis, osteomyelitis and septicaemia [2,3].

Recent national surveillance data from England, Wales and Northern Ireland found that over one third (38\%) of PWID report experiencing an abscess, sore or open wound at an injection site during the previous year [4]. A London-based study reported high lifetime prevalence of abscess and/or cellulitis, at $64 \%$ among a sample of 455 PWID [5]. Increasing incidence of bacterial infections and their complications is evident among PWID over recent years both in the United Kingdom (UK) and United States of America (USA) [6-8]. In the UK, bacterial SSTI treatment costs have been estimated to reach approximately $£ 77$ million annually [9].

Risk factors for bacterial infection include frequency of injecting, injection practice, and needle and syringe re-use and sharing [10-12]. Across England, Wales and Northern Ireland sharing of needles, syringes and other injecting equipment was reported by $43 \%$ of people who injected in the last month [4]. Morbidity associated with bacterial SSTI can be exacerbated by poor wound care [5, 6] and delays to seeking healthcare $[5,13,14]$. PWID face multiple barriers to health care access including stigma and poor treatment from service providers creating feelings of mistrust, anxiety and fear about seeking help, as well as practical difficulties accessing help [1416]

Given the significant and increasing public health concern about bacterial SSTI, there is an urgent need to develop acceptable, accessible and effective preventative interventions. Harm reduction services in England include opioid substitution treatment (OST) and needle and syringe programmes (NSP). Both offer promise for engaging with PWID to provide SSTI prevention and management interventions. There is also an opportunity to expand and scale up provision of such interventions to a wider range of providers, thus maximising opportunity for prevention among people who do not access traditional harm reduction services. 
There are limited interventions with a primary objective of reducing the risk of bacterial SSTI and the author are unaware of any interventions in the UK. One study in France reported that a face-to-face educational intervention informed by self-determination theory in harm reduction centres involving observation and education about injecting practices reduced the likelihood of unsafe injection practices and injection site complications (including abscess, infection, bruising, oedemas) at 12 months $[17,18]$. A second 6-week intervention co-designed with experts and PWID aiming to improve hand hygiene and using enablement, education and training from the Behaviour Change Wheel, demonstrated acceptability of face-to-face education and hand sanitiser provision, increased hand hygiene and reduced likelihood of injection-related complications [19]. Lastly, Philips et al [20], using the InformationMotivation-Behavioural Skills Model, highlighted that the 2-session SKIN intervention delivered in inpatient hospital units, which involves the provision of education about SSTIs, health seeking, injecting risk and hygiene practices, with individualised risk assessment, goal setting and a booster session reduced the rate of injection and increased likelihood of cleaning skin prior to injection [20]. These interventions focused on individual-level behaviours, within either harm reduction centres or hospital settings. There is a dearth of interventions which can be used flexibly by a range of professionals who engage with PWID in the community, focused more broadly on vein care and structural issues related to the risk of SSTI. For example, observation of injecting practices $[17,18]$ is unlikely to be feasible within a busy community pharmacy running NSP and OST.

Prevention interventions have not yet translated into population level reductions in SSTI [21]. We sought to address the gap in the UK evidence base by using the Person-Based Approach (PBA) to develop a new, individualised, behavioural, one-to-one intervention for PWID that aimed to prevent bacterial SSTI. The objectives were to:

i. Identify key behavioural issues, needs and challenges of promoting safer injecting practices among PWID;

ii. Develop a preliminary logic model outlining the proposed mechanisms of behaviour change;

iii. Develop and refine resources to be used as part of an individualised behavioural intervention, which address the key behavioural issues, needs and challenges identified and thus facilitate behaviour change and reduced risk of bacterial SSTIs.

\section{Methods}

\section{Ethics and consent}

Research approvals from the University of Bristol's Faculty of Health Sciences Research Ethics Committee (reference: 108304) were obtained to undertake the study overall (which included a pilot phase and interviews with participants and service providers). Consultations that informed intervention development were classified as Patient and Public Involvement therefore the University of Bristol's Faculty of Health Sciences Research Ethics Committee has waived consent for this study. However, good research practice was followed throughout. Prior to the consultation, the researcher explained the purpose and procedures of the consultation, and explicitly asking the respondent if they understood everything, and wanted to contribute. They were also informed they stop the consultation at any time. All methods were carried out in accordance with relevant guidelines and regulations.

\section{Research setting}

The study was undertaken in Bristol, the largest city in the Southwest of England where there are an estimated 4,940 opiate and/or crack users, the second highest rate in English cities, including a high proportion of people with complex needs and an ageing population [22]. The number of cases of methicillin-resistant Staphylococcus aureus (MRSA) among PWID has increased across Bristol, South Gloucestershire and North Somerset over recent years, reaching 16 cases (where injecting drug use was a confirmed risk factor) in 2018. In addition, the rate of MRSA colonisation among PWID is higher compared to the general population (8.7\% versus $1.5 \%$, which presents opportunities for colonised bacteria to pass through skin and enter the bloodstream, causing invasive disease [23].

\section{Study Conception}

The intervention design was conceived during the Local Government Association-funded, and Design Council-led 'Design in the Public Sector' (DiPS) programme (2018-9). Using the Design Council's Double Diamond Model (2019) [24] four priority areas were developed: 1) Improved infection prevention and control; 2) Optimisation of harm reduction practice in the community; 3) Increased access to healthcare among PWID, and; 4) Improved adherence to treatment for bacterial infections [25, 26]. 
This paper addresses one workstream focused around priority area two: development of a brief individualised 1:1 motivational intervention to be delivered by a range of service providers who have regular contact with PWID and can therefore deliver the intervention opportunistically in practice (e.g. shared care workers, pharmacists delivering OST and NSP, hostel staff).

The DiPS programme co-developed a prototype for the intervention comprising a tailored conversation focussing on reducing risky injecting practices, self-care, sign-posting, and information relating to hospital admission. The prototype intervention consisted of a laminated set of images of injecting equipment and paraphernalia (Fig. 1) used to structure the 1:1 conversation about injecting practice and to identify areas where risk could be reduced. Details of locally available sources of healthcare were also included, alongside images of different stages of infection to support decisions around self-care and healthcare seeking.

Preliminary feedback from PWID and service providers suggested that the prototype intervention could be useful, acceptable, and feasible. However, feedback suggested a requirement to further optimise the prototype to be deliverable within different settings used by PWID by service providers without specialist harm reduction knowledge and training. The need to expand the reach of harm reduction advice delivered in drug services was noted in this preliminary feedback. Additional funding was sought to enable further development of the intervention and piloting in a range of settings.

\section{Methodological approach}

In stage two of intervention development, we used the PBA to intervention planning and development [27]. This approach aims to combine behaviour change theory and mixed methods research to systematically investigate the beliefs, attitudes, needs and situation of the target intervention users during planning and development [27]. Through in-depth understanding of users' perspectives, the intervention can be designed or modified to ensure it is relevant, persuasive, accessible and engaging, and more successful to implement. This stage of intervention development comprised the following interrelated and iterative stages: (i) collating and analysing evidence; (ii) developing guiding principles; (iii) undertaking a behavioural analysis; (iv) developing a preliminary logic model, and; (v) designing and refining intervention materials.

\section{(i) Collating and analysing evidence}

Primary and secondary evidence were collated and analysed relating to key behaviours and structural barriers that the intervention would need to address to reduce harm from bacterial SSTIs.

\section{Review of the relevant literature}

Two members of the research team (HF \& JK) with input from academic experts collated mixed methods, secondary research evidence highlighting relevant behaviours and structural barriers to preventing bacterial SSTI. Additional handsearching of citations and reference lists supplemented the original documents identified.

\section{Consultations with target users and key stakeholders}

Consultations were conducted with intervention target users (PWID and service providers) and key stakeholders. Members of the study team ( $\mathrm{DH} \& \mathrm{CL}$ ), with specialist expertise in delivering harm reduction advice in a drug service, obtained feedback on the process of delivery of the prototype intervention from PWID $(n=15)$. Feedback and reflections of appropriateness, relevance, and potential for intervention effectiveness related to the prototype were captured using consistent templates to inform refinement of the intervention.

Consultations with service providers $(n=6)$ were also undertaken by a researcher (HF) to gain understanding about how the intervention could be delivered in practice, using a topic guide focused on: (i) current knowledge; (ii) intervention content and design, and; (iii) intervention delivery.

As evidence was gathered, potential refinements of the intervention prototype were discussed with key stakeholders $(n=11)$, who included an Assertive Engagement Worker (DH), the founder of a social enterprise that develops harm reduction equipment (AP), the chief executive of a drug and alcohol services charity (MT), multi-disciplinary academics (MH, JS), a pharmacist prescriber (JS), and public health professionals (GM, HE, DM). 
In line with the PBA [27], findings and feedback from target users and stakeholders were collated in a Table of Planning document in relation to the following areas of relevance: 'understanding context of potential intervention implementation', 'potential targets for intervention', 'potential strategies for intervention', 'presentation and format', and 'implementation'. The possible implications and intervention features required to address the findings/feedback were documented. Prioritisation for changes were based on the MoSCoW (Must have, Should have, Could have, Would like) criteria informed by the guiding principles [28].

\section{(ii) Developing guiding principles}

Guiding principles are a key feature of the PBA and are intended to maximise the acceptability of the intervention and future engagement [29]. They comprise a design objective and proposed intervention features which address the user/context-specific behavioural needs, issues, or challenges. These were iteratively developed based on understanding of the target users gained during the earlier stages.

\section{(iii) Undertaking a behavioural analysis}

The behavioural analysis aimed to identify behaviours to be targeted by the intervention and their potential barriers and facilitators. These were mapped onto constructs from the COM-B (capability, opportunity, motivation - behaviour) model of behaviour change and the Behaviour Change Wheel [30] to clearly describe the intervention processes and components, and behaviour change techniques [31].

\section{(iv) Logic model}

In line with the 2021 framework for developing complex interventions [32], a logic model was developed to provide a visual representation of the proposed mechanisms of change. This brings together the findings from the activities described previously and how these are anticipated to reduce harm from bacterial SSTI among PWID.

\section{(v) Design and refining of intervention materials}

We produced an initial design brief for Michael Linnell of Linnell Publications, a professional designer specialising in harm reduction, with whom the team had worked previously, to produce an updated prototype for the intervention materials.

Feedback on the intervention materials was obtained through further consultations organised with key stakeholders and PWID $(n=3)$. Feedback was elicited on their perceptions of the positive and negative aspects of the intervention materials, how it was presented, the design, and suggestions for new content or messages. The responses were collated in a Table of Changes document.

Modifications to the intervention materials were made in line with the guiding principles [29]. This considered whether they were likely to impact on behaviour change or a precursor to behaviour change (e.g. acceptability, feasibility, persuasiveness, motivation, engagement). Prioritisation for changes were based on the MoSCoW criteria [28].

Researchers (HF \& JK) also developed a short training manual containing information about the study, instructions for how to use the intervention materials, and a 'questioning and resources' guide to accompany it. A short online course was developed for service providers to provide the necessary information and knowledge underpinning delivery of the intervention. Key stakeholders were invited to review and comment on the documents to ensure the content was accurate, evidence-based and consistent with best harm reduction practice.

\section{Results}

\section{(i) Collating and analysing evidence}

\section{Review of the relevant literature}

The following behaviours were identified in the literature as related to the risk of developing bacterial SSTI among PWID: (i) handwashing / swabbing injection site practice prior to injecting is associated with reduced SSTI [33-38]; while an increased risk of SSTI is associated with (ii) vein damage from the overuse of acidifiers for injection preparation [39-41]; (iii) use of non-sterile water [42-44]; (iv) reuse of injecting equipment [25, 35, 37, 44-47]; and; (v) not rotating injecting sites (place on the body injected into) [48, 
49] (Table 1). In addition, maintaining vein access and minimising pain were identified as important concerns for PWID which can be utilised to enhance engagement with harm reduction interventions [49]. 
Table 1

Evidence for key behavioural issues and structural barriers the REACT intervention is trying to address

$\begin{array}{llll}\text { BEHAVIOURAL ISSUE } & \text { KEY } \\ \text { BEHAVIOURS } & \text { EVIDENCE FOR BEHAVIOUR } & \text { KEY FINDING(S) }\end{array}$

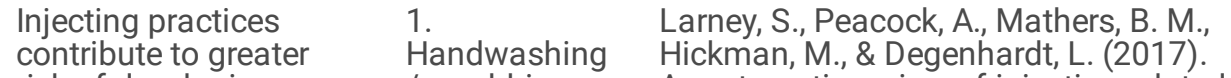
risk of developing bacterial skin and soft tissue infections among people who inject drugs
Four of six studies reported a reduction in skin infections associated with

cleaning injection sites; only one of four studies to examine hand-washing prior to injection found this behaviour to be significantly associated with reduced skin infections.

Vlahov D, Sullivan M, Astemborski J, Nelson K. Bacterial infections and skin cleaning prior to infection among intravenous drug users. Public Health Rep 1992, 107:595-598. [34]

Of all the persons surveyed, 556/1,057 $(52.6 \%)$ reported cleaning their skin prior to injection at any time and $173 / 1,057$ $(16.4 \%)$ reported cleaning their skin all the time in the 6 months before the interview.
The frequency of subcutaneous abscesses was lower among those who reported skin cleaning all the time; a similar trend was noted for frequency of endocarditis.

Murphy E, DeVita D, Liu H, Vittinghoff E, Leung P, Ciccarone D, Edlin B. Risk factors for skin and soft-tissue abscesses among injection drug users: a case-control study. Clin Infect Dis. 2001. [35]

Swabbing the injection site with alcohol before injection was found to have a protective effect against skin and softtissue abscesses. Significantly fewer people who had developed abscesses, in comparison with controls, had ever used alcohol to clean their skin before drug injection $(p<001)$.

Dwyer $\mathrm{R}$, et al. Prevalence's and correlates of non-viral injecting-related injuries and diseases in a convenience sample of Australian injecting drug users. Drug and Alcohol Dependence 2009; 100: 9-16. [36]

Hope V, Kimber J, Vickerman P, Hickman M, Ncube F. Frequency, factors and costs associated with injection site infections: findings from a national multi-site survey of injecting drug users in England. BMC Infect Dis. 2008 Sep 18;8:120. [37]

Stein, M. D., Phillips, K. T., Herman, D. S., Keosaian, J., Stewart, C., Anderson, B. J., \& Liebschutz, J. (2020). Skincleaning among hospitalized people who inject drugs: a randomized controlled trial. Addiction. [38]
Potentially serious or serious injectingrelated injuries and disease associated with not always washing hands before injection in the previous 12 months (aOR: $9.3,2.1-41.8)$.

Weak evidence that cleaning injection site every time in the last 4 weeks was associated with a reduced prevalence of injection site infection (OR: 0.6, 0.4-0.8).

$60 \%$ of participants reported 'rarely or never' cleaning their skin before injecting during the past three months. 
2. Overuse of acids
Harris, M., Scott, J., Wright, T. et al. Injecting-related health harms and overuse of acidifiers among people who inject heroin and crack cocaine in London: a mixed-methods study. Harm Reduct J, 2019: 16, 60. [41]

Overuse of acidifiers in injection preparation is common among people who inject drugs in the UK and could play a causative role in venous damage and associated sequelae (skin and soft tissue infection and associated complications).

Of 418 participants who provided an estimate, 150 (36\%) used more than $1 / 2$ a sachet of acidifier, with 127 (30\%) using a whole sachet or more.

Associations observed between acidifier overuse, femoral injecting and deep vein thrombosis, but not skin and soft tissue infections. Painful injections and damage to peripheral veins were common and often attributed by participants to the use of citric acid.

Ciccarone D, Harris M. Fire in the vein: Heroin acidity and its proximal effect on users' health. Int J Drug Policy. 2015;26(11):1103-1110. [39]

Harris M. The 'do-it-yourself' New Zealand injecting scene: implications for harm reduction.

Int J Drug Policy. 2013; Jul; 24(4):2813. [40]
Harris, M, Scott, J, Hope, V, Wright, T, McGowan, C \& Ciccarone, D. Navigating environmental constraints to injection preparation: the use of saliva and other alternatives to sterile water among unstably housed PWID in London. Harm Reduction Journal, 2020: 17 (1). 24-. [42]

Lloyd-Smith, E., Wood, E., Zhang, R., Tyndall, M. W., Montaner, J. S., \& Kerr, T. Risk factors for developing a cutaneous injection-related infection among injection drug users: a cohort study. BMC public health, 2008: 8, 405. [43]

Hope, V., Marongiu, A., Parry, J., \& Ncube, F. The extent of injection site infection in injecting drug users: Findings from a national surveillance study. Epidemiology and Infection, 2010; 138(10), 1510-1518. [44]
Preliminary findings show that different heroin source-forms and preparations have a two-log difference in acidity.

Loss of functioning veins (venous sclerosis) is a root cause of suffering for long-term heroin injectors. In addition to perpetual frustration and loss of pleasure/esteem, venous sclerosis leads to a myriad of medical consequences including skin infections, for example, abscess.

Opioid injectors in New Zealand using very small amounts of citric acid suffer little vein damage and rarely get skin and soft tissue infections.

Multiple constraints to sourcing sterile water for injection preparation reported.

Participant accounts suggest injection preparation with solvents including puddle water, toilet cistern water, whisky, cola soda and saliva when injecting in public and semi-public spaces. This relates to both behavioural and environmental constraints that increase risk of infection.

No strong evidence that using a puddle to inject was a risk factor for developing a cutaneous injection-related infection among people who inject drugs (OR 1.32, $0.83-2.11)$.

Higher levels of reported symptoms of injection site infection associated with reusing water to flush syringes (aOR:1. 28, 1. 03-1. 59). 


\begin{tabular}{|c|c|c|c|}
\hline BEHAVIOURAL ISSUE & $\begin{array}{l}\text { KEY } \\
\text { BEHAVIOURS }\end{array}$ & EVIDENCE FOR BEHAVIOUR & KEY FINDING(S) \\
\hline & \multirow[t]{8}{*}{$\begin{array}{l}\text { 4. Reuse of } \\
\text { injecting } \\
\text { equipment }\end{array}$} & \multirow{2}{*}{$\begin{array}{l}\text { Dunleavy K, Hope V, Roy K, Taylor A. } \\
\text { The experiences of people who inject } \\
\text { drugs of skin and soft tissue infections } \\
\text { and harm reduction: A qualitative } \\
\text { study. Int J Drug Policy. } 2019 \\
\text { Mar;65:65-72. [25] }\end{array}$} & $\begin{array}{l}\text { Depletion of injecting equipment could } \\
\text { lead to re-use of needles, seen as a cause } \\
\text { of SSTI by some participants. }\end{array}$ \\
\hline & & & $\begin{array}{l}\text { Needles were re-used because of lack of } \\
\text { time or inability to replenish supplies due, } \\
\text { for example, to weekend closing of } \\
\text { convenient NSP or if they woke in the } \\
\text { middle of the night. This relates to } \\
\text { structural barriers as well as behavioural } \\
\text { barriers. }\end{array}$ \\
\hline & & $\begin{array}{l}\text { Hope V, Kimber J, Vickerman P, } \\
\text { Hickman M, Ncube F. Frequency, } \\
\text { factors and costs associated with } \\
\text { injection site infections: findings from } \\
\text { a national multi-site survey of injecting } \\
\text { drug users in England. BMC Infect Dis. } \\
2008 \text { Sep 18;8:120. [37] }\end{array}$ & $\begin{array}{l}\text { Reporting an injection site infection was } \\
\text { associated with cleaning needles/ } \\
\text { syringes for reuse (aOR:1.5, 1.1-2.1). }\end{array}$ \\
\hline & & $\begin{array}{l}\text { Darke S, Ross J, Kaye S: Physical } \\
\text { injecting sites among injecting drug } \\
\text { users in Sydney, Australia. Drug } \\
\text { Alcohol Depend 2001, 62:77-82. [45] }\end{array}$ & $\begin{array}{l}\text { Participants who had borrowed used } \\
\text { injecting equipment in the preceding } \\
\text { month had significantly more current } \\
\text { health-related problems at their injecting } \\
\text { sites than other participants ( } 3.1 \text { vs. } 2.1, \mathrm{t} \\
=3.7, \mathrm{P}<0.001) \text {. }\end{array}$ \\
\hline & & $\begin{array}{l}\text { Hope, V., Marongiu, A., Parry, J., \& } \\
\text { Ncube, F. The extent of injection site } \\
\text { infection in injecting drug users: } \\
\text { Findings from a national surveillance } \\
\text { study. Epidemiology and } \\
\text { Infection, 2010; 138(10), 1510-1518. } \\
\text { [44] }\end{array}$ & $\begin{array}{l}\text { Higher levels of reported symptoms of } \\
\text { infections were associated with sharing } \\
\text { filters in the last four weeks (aOR: } 1.31 \text {, } \\
09-1.59) \text {. No strong evidence was found } \\
\text { for sharing spoons. }\end{array}$ \\
\hline & & \multirow[t]{2}{*}{$\begin{array}{l}\text { Rance J, Rhodes T, Fraser S, Bryant J, } \\
\text { Treloar C. Practices of partnership: } \\
\text { Negotiated safety among couples who } \\
\text { inject drugs. Health (London, England: } \\
\text { 1997). 2018;22(1):3-19. [46] }\end{array}$} & $\begin{array}{l}75 \% \text { of participants reported } \\
\text { sharing within their partnership. Only one } \\
\text { participant reported sharing with someone } \\
\text { other than their partner, while eight } \\
\text { couples reported never sharing. }\end{array}$ \\
\hline & & & $\begin{array}{l}\text { Of the } 26 \text { couples who reported sharing } \\
\text { needle-syringes, } 20 \text { believed they were } \\
\text { hepatitis C virus concordant ( } 8 \mathrm{HCV} \\
\text { negative and } 12 \mathrm{HCV} \text { positive) and } 14 \\
\text { discordant ( } 8 \mathrm{HCV} \text {-positive men and } 6 \\
\text { HCV-positive women). }\end{array}$ \\
\hline & & $\begin{array}{l}\text { Murphy E, DeVita D, Liu H, Vittinghoff } \\
\text { E, Leung P, Ciccarone D, Edlin B. Risk } \\
\text { factors for skin and soft-tissue } \\
\text { abscesses among injection drug users: } \\
\text { a case-control study. Clin Infect Dis. } \\
\text { 2001. [35] }\end{array}$ & $\begin{array}{l}\text { Use of a needle after someone else had } \\
\text { used it }(p=0.005) \text { and use of a dirty } \\
\text { needle }(p<0.001) \text { were both significantly } \\
\text { more common among cases who reported } \\
\text { a skin and soft-tissue abscess than } \\
\text { among controls. }\end{array}$ \\
\hline & & \multirow{2}{*}{$\begin{array}{l}\text { Wright NM, Tompkins CN, Jones L. } \\
\text { Exploring risk perception and } \\
\text { behaviour of homeless injecting drug } \\
\text { users diagnosed with hepatitis C. } \\
\text { Health Soc Care Community. } 2005 \\
\text { Jan;13(1):75-83. [47] }\end{array}$} & $\begin{array}{l}\text { Participants reported sharing injecting } \\
\text { equipment, in particular spoons and filters. }\end{array}$ \\
\hline & & & $\begin{array}{l}\text { Re-using cleaned needles despite being } \\
\text { aware that cleaning may not be effective } \\
\text { in reducing the risk of hepatitis C } \\
\text { transmission was also identified. }\end{array}$ \\
\hline
\end{tabular}




\begin{tabular}{|c|c|c|c|}
\hline BEHAVIOURAL ISSUE & $\begin{array}{l}\text { KEY } \\
\text { BEHAVIOURS }\end{array}$ & EVIDENCE FOR BEHAVIOUR & KEY FINDING(S) \\
\hline & \multirow[t]{4}{*}{$\begin{array}{l}\text { 5. Rotating } \\
\text { sites }\end{array}$} & \multirow{2}{*}{$\begin{array}{l}\text { Hope V, Parry J, Ncube F, Hickman M. } \\
\text { Not in the vein: 'missed hits', } \\
\text { subcutaneous and intramuscular } \\
\text { injections and associated harms } \\
\text { among people who inject psychoactive } \\
\text { drugs in Bristol, United Kingdom. Int J } \\
\text { Drug Policy. 2016 Feb;28:83-90. [48] }\end{array}$} & $\begin{array}{l}\text { More than half of those surveyed reported } \\
\text { having had a 'missed hit', and for a quarter } \\
\text { this happened at least once a month, with } \\
\text { around one in six reporting having a } \\
\text { 'missed hit' more than four times a month. }\end{array}$ \\
\hline & & & $\begin{array}{l}\text { Those who reported that they had } \\
\text { experienced a 'missed hit' were twice as } \\
\text { likely to also report having had symptoms } \\
\text { of injection site infections and injuries. }\end{array}$ \\
\hline & & \multirow[t]{2}{*}{$\begin{array}{l}\text { Harris M, Rhodes T. Venous access } \\
\text { and care: harnessing pragmatics in } \\
\text { harm reduction for people who inject } \\
\text { drugs. Addiction. 2012;107(6):1090-6. } \\
\text { [49] }\end{array}$} & $\begin{array}{l}\text { The facilitation of venous access and care } \\
\text { was an initial and enduring rationale for } \\
\text { safe injecting practices. Difficult venous } \\
\text { access resulted in increased } \\
\text { contamination of injecting environments } \\
\text { and transitions to femoral injecting. }\end{array}$ \\
\hline & & & $\begin{array}{l}\text { Advice and information on how to avoid } \\
\text { venous sclerosis, and how to find and } \\
\text { safely access less visible veins, was } \\
\text { desired by the majority. }\end{array}$ \\
\hline $\begin{array}{l}\text { ENVIRONMENTAL } \\
\text { STRUCTURE }\end{array}$ & $\begin{array}{l}\text { KEY } \\
\text { STRUCTURAL } \\
\text { CONSTRAINT }\end{array}$ & EVIDENCE FOR STUCTURAL BARRIER & KEY FINDING(S) \\
\hline \multirow{6}{*}{$\begin{array}{l}\text { Structural constraints } \\
\text { act as barrier to safer } \\
\text { injecting practices and } \\
\text { contribute to greater } \\
\text { risk of developing } \\
\text { bacterial skin } \\
\text { infections among } \\
\text { people who inject } \\
\text { drugs }\end{array}$} & \multirow{3}{*}{$\begin{array}{l}\text { Access to } \\
\text { handwashing } \\
\text { facilities } \\
\text { among } \\
\text { homeless } \\
\text { people who } \\
\text { inject drugs }\end{array}$} & \multirow{2}{*}{$\begin{array}{l}\text { Harris, M, Scott, J, Hope, V, Wright, } \\
\text { T, McGowan, C \& Ciccarone, D. } \\
\text { Navigating environmental constraints } \\
\text { to injection preparation: the use of } \\
\text { saliva and other alternatives to sterile } \\
\text { water among unstably housed PWID in } \\
\text { London. Harm Reduction Journal, } \\
\text { 2020: } 17 \text { (1). 24-. [42] }\end{array}$} & $\begin{array}{l}\text { Funding cuts have impacted not only on } \\
\text { housing and welfare provision but access } \\
\text { to clean water on the city streets among } \\
\text { unstably housed people who inject drugs. }\end{array}$ \\
\hline & & & \multirow{2}{*}{$\begin{array}{l}\text { Participants reported injecting in a variety } \\
\text { of outdoor public places whilst they were } \\
\text { homeless, including derelict buildings, } \\
\text { back alleys, bushes and underneath } \\
\text { bridges. }\end{array}$} \\
\hline & & $\begin{array}{l}\text { Wright N, Tompkins CN, Jones L. } \\
\text { Exploring risk perception and } \\
\text { behaviour of homeless injecting drug } \\
\text { users diagnosed with hepatitis C. } \\
\text { Health Soc Care Community. } 2005 \\
\text { Jan;13(1):75-83. [47] }\end{array}$ & \\
\hline & $\begin{array}{l}\text { Citric acid } \\
\text { sachet size }\end{array}$ & $\begin{array}{l}\text { Harris, M., Scott, J., Wright, T. et } \\
\text { al. Injecting-related health harms and } \\
\text { overuse of acidifiers among people } \\
\text { who inject heroin and crack cocaine in } \\
\text { London: a mixed-methods study. Harm } \\
\text { Reduct J, 2019: 16, 60. [41] }\end{array}$ & $\begin{array}{l}\text { Acid sachet size poses a constraint to } \\
\text { good practice. The sachet size is a strong } \\
\text { signifier of appropriate quantity. }\end{array}$ \\
\hline & \multirow[t]{2}{*}{$\begin{array}{l}\text { Access to } \\
\text { sterile water } \\
\text { for injection } \\
\text { preparation }\end{array}$} & \multirow[t]{2}{*}{$\begin{array}{l}\text { Harris, M, Scott, J, Hope, V, Wright, } \\
\text { T, McGowan, C \& Ciccarone, D. } \\
\text { Navigating environmental constraints } \\
\text { to injection preparation: the use of } \\
\text { saliva and other alternatives to sterile } \\
\text { water among unstably housed PWID in } \\
\text { London. Harm Reduction Journal, } \\
\text { 2020: } 17 \text { (1). 24-. [42] }\end{array}$} & $\begin{array}{l}\text { Funding cuts have impacted not only on } \\
\text { housing and welfare provision but access } \\
\text { to clean water on the city streets (e.g. } \\
\text { closure of public toilet and increased } \\
\text { security in pubs and cafes) among } \\
\text { unstably housed people who inject drugs. }\end{array}$ \\
\hline & & & $\begin{array}{l}\text { Drug treatment services, facing sustained } \\
\text { budgets cuts of at least } 18 \% \text {, have } \\
\text { reduced costs where possible, impacting } \\
\text { on the availability of water provision in } \\
\text { needle and syringe programme equipment } \\
\text { packs. }\end{array}$ \\
\hline
\end{tabular}




\begin{tabular}{|c|c|c|c|}
\hline BEHAVIOURAL ISSUE & $\begin{array}{l}\text { KEY } \\
\text { BEHAVIOURS }\end{array}$ & EVIDENCE FOR BEHAVIOUR & KEY FINDING(S) \\
\hline & \multirow[t]{2}{*}{$\begin{array}{l}\text { Access to } \\
\text { sterile } \\
\text { equipment }\end{array}$} & \multirow[t]{2}{*}{$\begin{array}{l}\text { McNeil R, Small W. 'Safer environment } \\
\text { interventions': a qualitative synthesis } \\
\text { of the experiences and perceptions of } \\
\text { people who inject drugs. Soc Sci Med. } \\
2014 \text { Apr;106:151-8. [50] }\end{array}$} & $\begin{array}{l}\text { Needle and syringe programmes increase } \\
\text { access to material resources and safer } \\
\text { injecting education. This is a facilitating } \\
\text { factor. }\end{array}$ \\
\hline & & & $\begin{array}{l}\text { Participants expressed understanding that } \\
\text { safer environment interventions reduced } \\
\text { an array of risks by changing physical and } \\
\text { social environments (Kerr et al., } \\
\text { 2007; Small et al., 2012a). }\end{array}$ \\
\hline & \multirow[t]{3}{*}{$\begin{array}{l}\text { Risky } \\
\text { injecting } \\
\text { environment }\end{array}$} & \multirow{2}{*}{$\begin{array}{l}\text { Dunleavy K, Hope V, Roy K, Taylor A. } \\
\text { The experiences of people who inject } \\
\text { drugs of skin and soft tissue infections } \\
\text { and harm reduction: A qualitative } \\
\text { study. Int J Drug Policy. } 2019 \\
\text { Mar;65:65-72. [25] }\end{array}$} & $\begin{array}{l}\text { Participants reported injecting in indoor } \\
\text { environments that were unhygienic and } \\
\text { higher risk practice when injecting new } \\
\text { psychoactive substances. }\end{array}$ \\
\hline & & & $\begin{array}{l}\text { Participants' experience of SSTIs could } \\
\text { cause panic and stigma; there was limited } \\
\text { knowledge of SSTIs prior to first-hand } \\
\text { experience. }\end{array}$ \\
\hline & & $\begin{array}{l}\text { Wright N, Tompkins CN, Jones L. } \\
\text { Exploring risk perception and } \\
\text { behaviour of homeless injecting drug } \\
\text { users diagnosed with hepatitis C. } \\
\text { Health Soc Care Community. } 2005 \\
\text { Jan;13(1):75-83. [47] }\end{array}$ & $\begin{array}{l}\text { Participants reported injecting in a variety } \\
\text { of outdoor public places whilst they were } \\
\text { homeless, including derelict buildings, } \\
\text { back alleys, bushes and underneath } \\
\text { bridges. Participants also reported } \\
\text { urgency of injecting outside. }\end{array}$ \\
\hline
\end{tabular}

There was also evidence that structural constraints act as barriers to safer injecting practices and contribute to greater risk of developing bacterial SSTI among PWID. In brief, these included: (i) a lack of access to handwashing facilities when injecting in public spaces [42, 47]; (ii) citric acid sachets containing more than is needed for a single injection [41]; (iii) limited access to sterile water for injection preparation [42]; (iv) lack of access to sterile injecting equipment [50], and; (v) riskier injecting environment including public/semi-public environments $[25,47]$ (Table 1$)$.

\section{Consultations with target users and key stakeholders}

Consultations were undertaken in person with PWID $(n=15)$ between February and March 2020 and service providers by telephone identified as potential intervention deliverers $(n=6)$ between May and June 2020. Multi-disciplinary stakeholders $(n=11)$ were consulted during online meetings held between August 2020 and March 2021.

Table 2 demonstrates that target users discussed their injecting practices with $\mathrm{DH}$ and $\mathrm{CL}$ openly. They described injecting outdoors or in public spaces as the main barrier to safer injecting practice, since injecting was rushed resulting in more opportunities for contamination. An additional structural factor acting as a barrier to safer injecting is that equipment such as sterile water to prepare injections and post injection swabs to stem bleeding were not available from local drug services. While they acknowledged there were areas of injecting practice which could be improved, challenging the long-held beliefs of PWID and changing entrenched behaviours were anticipated to be difficult. A knowledge-behaviour gap related to habitual behaviours and structural factors was highlighted with individuals citing good knowledge of 'best practice' which they reported to follow although some accounts appeared inconsistent with a history of infections. 
Table 2

Key findings from consultations with service providers and people who inject drugs

Themes

Summary of Findings

Action points or intervention development

\section{(i) Service providers}

Acceptability of - All service providers were receptive to the aims of the intervention intervention and expressed willingness to be involved in future research activities to test it with their clients as part of the study.

Professional - Service providers frequently discussed with pride the importance of judgements relationships they had developed with their clients.

- Delivery of the intervention would require a judgement by the service provider as to whether the client would be receptive at all, or during an encounter.

- Clients may be aware that their injection process differs from lower risk practice. As such, time and attention, and an understanding that some may not wish to describe their injection practice in detail, was required by service providers.

- Relevance of intervention messages and changes to injecting practices / health seeking behaviour could be increased if delivered to the client at a time of crisis (e.g. presenting with wound site infection).

Intervention - Some service providers had limited time to dedicate to intervention delivery \& training needs delivery $(5-10$

- The intervention should be deliverable in the length of time minutes). This could also be influenced by how receptive a client was during an encounter.

- All service providers could access a confidential space to deliver the intervention.

- Allow service providers autonomy and judgement to decide who and when the intervention is delivered to.

- Preferences for training related to the intervention included both face-to-face and online modules.

Characteristics - Some service providers perceived that an intervention of this type of target users would be most relevant to clients with a shorter injecting history.

- Greater barriers to safer injecting practices among clients with more chaotic lifestyles, long injecting history and complex social and health needs were noted.

- Openness of clients to discuss injecting practices appeared to differ geographically. Service providers who worked with clients in South Bristol commented that their job role and stigma created prevented open discussions and uncertainty as to whether their clients injected or not. This appeared less of a barrier among service providers based in East and Central Bristol. However, it is possible that this is related to the role of the provider as these were not consistent between geographical areas. available to the service provider (5 minutes upwards).

- Develop training module that can be delivered either face-to-face and online.

- Allow service providers autonomy and judgement to decide who and when the intervention is delivered to.

- Develop guidance for service providers to overcome stigma around open discussion about injecting practices.

\section{(ii) People who inject drugs}

$\begin{array}{ll}\text { Structural } & \text { - Injecting outdoors presented most danger to safer injecting } \\ \text { barriers to } & \text { practices - rushed and more opportunities for contamination. }\end{array}$ barriers to change
- Lack of access to equipment like sterile water to prepare injections and post injection swabs acted as barriers to safer injecting practices with some people reporting using a range of higher risk water options and either not swabbing or using pre-injection swabs after injecting.
- Address structural barriers as part of the intervention 


$\begin{array}{lll}\text { Themes Summary of Findings } & \begin{array}{l}\text { Action points or intervention } \\ \text { development }\end{array}\end{array}$

Characteristics - Challenging beliefs of people who have been using drugs a longof target users term with entrenched behaviours is difficult - especially if no history of bacterial infections at wound sites.

- There was often scope for improving some aspect of the injecting practice. A wide range of different areas for harm reduction strategies were apparent.

- Encouraging clients to change one key aspect of their injecting practice is most realistic given habits which may have been formed over decades. Training should reinforce to service providers that this may be challenging for their clients.

- Given the complexity and range of injecting practices identified as part of the consultation, a 'one size fits all' approach is not appropriate. Service providers should tailor harm reduction advice specifically to areas identified as more risky following (open) discussion with the client.

Delivery of intervention \& training needs
- Clients may have good knowledge and report 'best practice' around injecting behaviours, although this may not always correspond with their history of wound site infections.

- Images being used as a 'talking point' can help encourage more open discussions, but these may not always be reflective of actual practice.
- Service providers should be aware that social desirability bias may impact response from clients. Example questions to probe the client further could be provided as part of the training manual for service providers.

\section{REACT Steering Group, Academic and Clinical Experts.}

Context to $\quad$ The main causes of bacterial infections must underpin targets for implementation

behaviour change, including: hygiene measures, vein damage, equipment reuse, sharing, not rotating sites, subcutaneous injection, use of water.

- Stigma and shame are major barriers to overcome in this intervention.

- Encouraging clients to change one key aspect of injecting practice is most realistic in light of habitual practice which may have developed over decades.
- Focus on safer injection practices is required, incorporating reuse of needs, use of acids, water and rotating sites.

- Provide resources to promote better hygiene.

- Service providers should tailor harm reduction advice specifically to areas identified as most risky following open discussion with client.

- Provide guidance for service providers to overcome stigma around open discussion of injection practices.

- Universal messages about preventing infection should be include in the training manual.

- Frame intervention around priorities of PWID.

and care, have the potential to re-engage clients.

- Small, manageable changes are possible. Structural barriers can be addressed by supporting people to navigate existing structures differently e.g. provide swabs as part of intervention.

- Providers outside of specialist drug treatment services need to be skilled in basic harm reduction practice. Those delivering the intervention need to be knowledgeable and non-judgemental.

- Delivery to coincide with teachable moments may encourage engagement with the intervention.

- Address some structural barriers, in part, through practical resources to enable safer injecting e.g. hand sanitiser, swabs with instructions for correct use.

- Training is required to support service providers to deliver the intervention.

- Address structural barriers (as above).

- The focus of the intervention should be on primary prevention of bacterial infections

- Do not include goal setting.

- Goal setting has the potential for increased stigma, sense of failure and focuses on individual rather than structural barriers. 


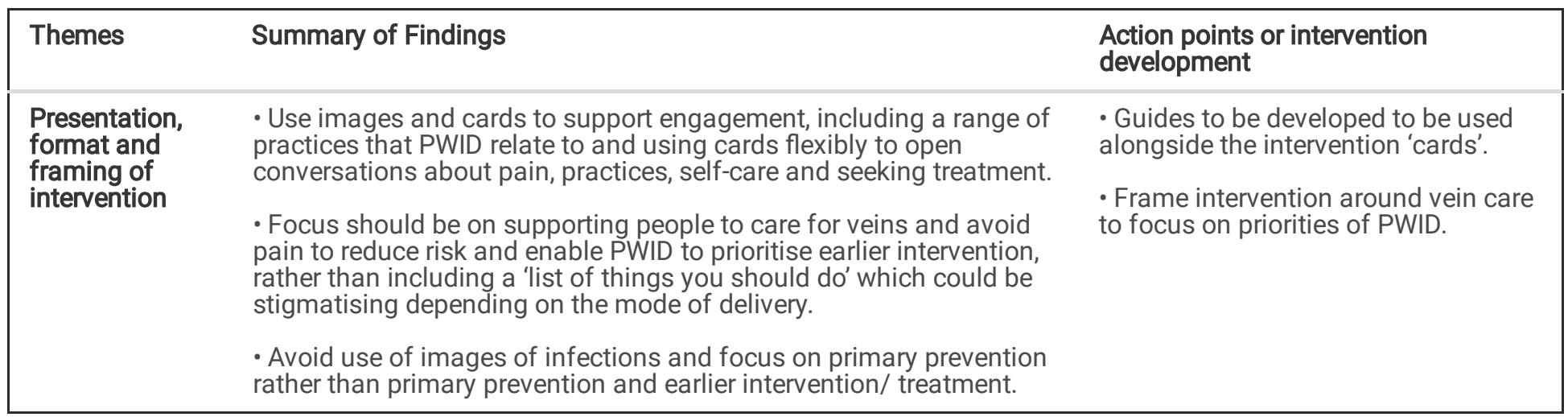

[Table 2. Key findings from consultations with service providers and people who inject drugs]

Providers highlighted the importance of existing relationships with clients and judging whether clients would be receptive to the intervention. They suggested that those with a shorter injecting history might be more receptive to the messages in the intervention compared to clients with more complex health and social needs and a longer injecting history. Stigma and willingness to discuss injecting practices also varied across the city which might affect uptake of the intervention. The intervention needs to be flexible to meet the limited time available to service providers and how receptive the client is to receiving the intervention.

In line with the literature, PWID and stakeholders noted the need to address the structural barriers cited above. PWID also highlighted the need to tailor the intervention to individual risks, and encouragement to change one aspect of injection practice if habits are entrenched.

Lastly, stakeholders' views and perspectives echoed barriers to behaviour change identified in the literature review (Table 1). Stakeholders highlighted the importance of framing the intervention around the priorities of PWID, particularly minimising pain and supporting vein access to support engagement with the intervention; and the need to avoid stigmatising PWID during the intervention. The latter could be achieved by not using goal setting which has the potential to increase stigma, a sense of failure and focuses on individual level rather than structural barriers and ensuring that the intervention is delivered by trained service providers with sensitivity (Table 2).

Refinement of the intervention

The intervention was refined using findings from the literature review and consultations. The initial intervention prototype included several interrelated topics spanning primary prevention and treatment of infection: improving injecting practices, self-care of existing bacterial SSTI, and sign-posting to relevant healthcare services. The intervention focus was realigned and narrowed to primary prevention: addressing the primary causes of bacterial SSTI among PWID. The following intervention themes were identified as key risk factors to developing bacterial SSTI: (1) poor handwashing and swabbing practice; (2) overuse of acids; (3) use of non-sterile water; (4) reusing injecting equipment, and; (5) not rotating sites.

Refining the focus of the intervention also enabled better alignment to the priorities of the target users - 'keeping veins healthier for longer' and 'minimising pain' - to maximise engagement with the intervention [49].

Practical resources tailored to participants were added to the intervention materials to support safer injecting practices (e.g. sterile water ampoules, hand sanitisers, wipes with instructions for correct use, street injecting kits developed in response to research findings [42]). These materials were supplemented by information resources already developed as required [51].

\section{(ii) Development of guiding principles}

The guiding principles include three aims of the REACT intervention: (i) address priorities of PWID by supporting improved vein care and minimisation of pain; (ii) provide appropriate resources to enable less harmful injecting practices and overcome barriers to safer injecting practice at the structural level, and; (iii) deliver flexibly to meet the needs of target population (Table 3). 
Table 3

Guiding principles for REACT intervention.

\section{Design objectives that address each key issue \\ Key intervention features relevant to each design objective}

i) To address priorities of people who inject drugs

by making changes to their

injecting practices to keep their

veins healthier for longer and

minimise pain
Provide tailored harm reduction advice to include discussion of the following topics:

(i) environment person injects in

(ii) handwashing/swabbing

(iii) use of acids

(iv) use of water

(v) reuse of equipment (needles, cookers, filters)

(vi) rotating sites

Use of motivational interview techniques

Positive, non-judgemental conversation between service provider and client

Provision of following resources to help support harm reduction behaviours:

- "Let's give bacteria the Boot" SDF leaflet

- Hand sanitisers and wipes (with instructions for use)

- Injecting tips: \#1 bacterial infections Exchange supplies leaflet

- Injecting tips: \#2 prevention and care: abscesses and ulcers Exchange supplies leaflet

- Injecting tips: \#3 staying safe on the street Exchange supplies leaflet

- Water ampoules

- Street injecting kit

- Citric packets (with instructions for use)

- Use of intervention 'cards' as appropriate to act as a prompt to discussion on different topics

- Delivery of shorter version to fit within constraints of appointment time or priorities of client

- Tailor provision of resources depending on needs of client (e.g. previous experience of bacterial infections; difficulties prioritising safer injecting practice due to dependence; lack of opportunities to follow safer injecting practices; entrenched injecting practices; good knowledge of 'best practice'; experience of stigma and shame meaning conversations about injecting behaviours are difficult)

- Intervention delivery should be within the context of a confidential space to facilitate open discussion about stigmatised behaviours

- Utilise existing relationship between client and service provider to overcome shame in open discussions about behaviours

\section{(iii) Undertaking a behavioural analysis}

Mapping the target behaviour and associated barriers alongside the intervention strategies, illustrates that the REACT intervention employs three intervention functions from the COM-B model: psychological capability, reflective motivation, and physical opportunity. A further six intervention functions: (education, training, persuasion, environmental restructuring, and enablement) from the Behaviour Change Wheel are used. In turn, these are enacted by six behaviour change techniques: instruction on how to perform a behaviour, information about health consequences, anticipated regret, prompts/cues, pros and cons, and restructuring the social 
environment. This analysis provided an in-depth understanding of the behaviours and structural barriers the REACT intervention aims to target, in addition to the mechanisms through which change is anticipated (Table 4). 
Table 4

Behavioural analysis of REACT intervention using the COM-B model of behaviour and Behaviour Change Wheel

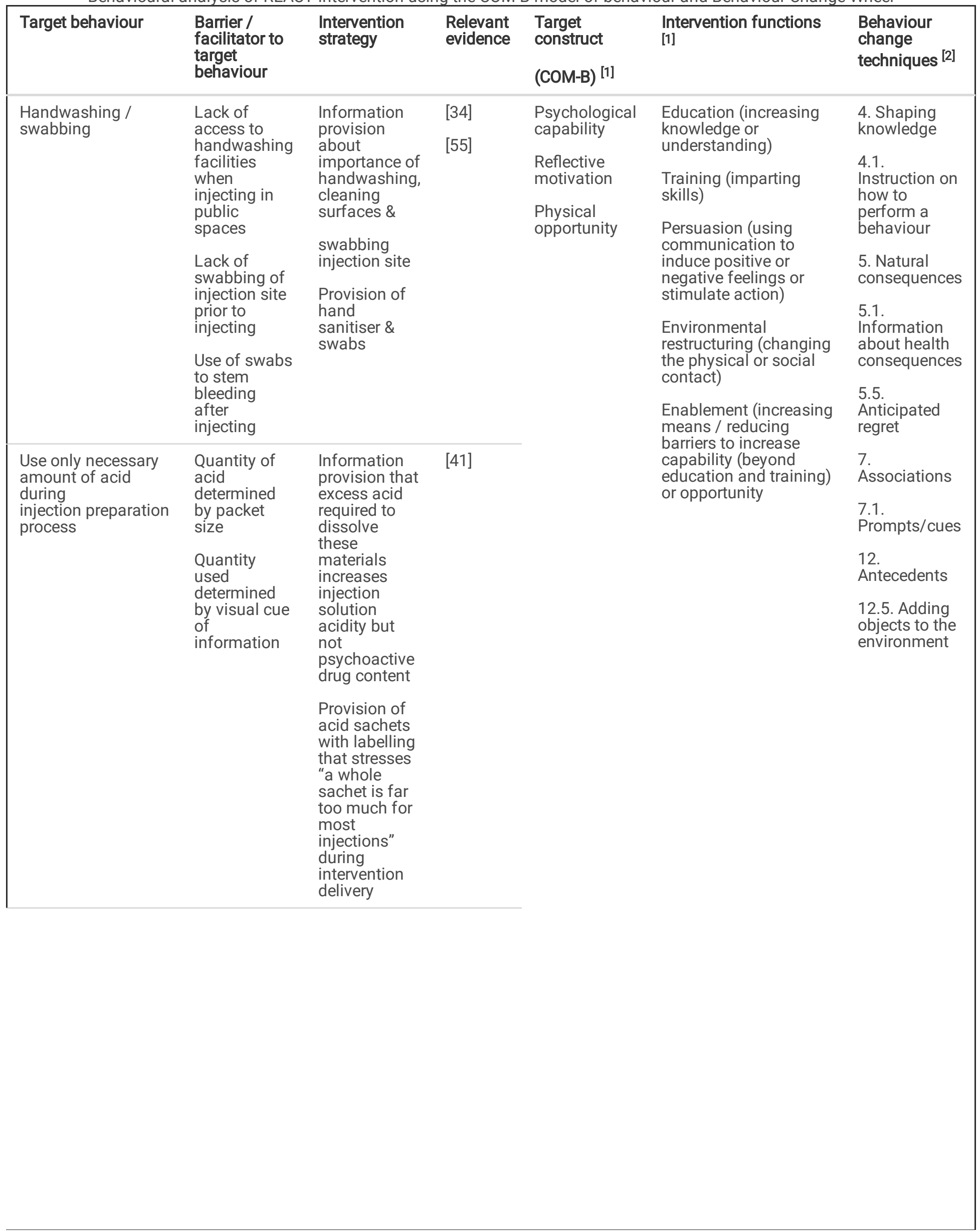




\begin{tabular}{|c|c|c|c|c|c|c|}
\hline Target behaviour & $\begin{array}{l}\text { Barrier / } \\
\text { facilitator to } \\
\text { target } \\
\text { behaviour }\end{array}$ & $\begin{array}{l}\text { Intervention } \\
\text { strategy }\end{array}$ & $\begin{array}{l}\text { Relevant } \\
\text { evidence }\end{array}$ & $\begin{array}{l}\text { Target } \\
\text { construct } \\
(\mathrm{COM}-\mathrm{B})^{[1]}\end{array}$ & $\begin{array}{l}\text { Intervention functions } \\
\text { [1] }\end{array}$ & $\begin{array}{l}\text { Behaviour } \\
\text { change } \\
\text { techniques }{ }^{[2]}\end{array}$ \\
\hline $\begin{array}{l}\text { Use of water for } \\
\text { injection preparation }\end{array}$ & $\begin{array}{l}\text { Lack of } \\
\text { access to } \\
\text { sterile water } \\
\text { when } \\
\text { injecting in } \\
\text { public } \\
\text { spaces } \\
\text { Measures } \\
\text { such as the } \\
\text { closure of } \\
\text { public toilets } \\
\text { and } \\
\text { increased } \\
\text { security in } \\
\text { pubs and } \\
\text { cafes have } \\
\text { reduced } \\
\text { access to } \\
\text { clean water } \\
\text { for homeless } \\
\text { people. } \\
\text { Sterile water } \\
\text { for injection } \\
\text { is not } \\
\text { included in } \\
\text { most } \\
\text { injection } \\
\text { packs } \\
\text { because of } \\
\text { local budget } \\
\text { constraints. }\end{array}$ & $\begin{array}{l}\text { Information } \\
\text { provision } \\
\text { about } \\
\text { hierarchy of } \\
\text { water } \\
\text { (intervention } \\
\text { delivery \& } \\
\text { leaflet) } \\
\text { Provision of } \\
\text { water } \\
\text { ampoules / } \\
\text { Street } \\
\text { injecting kits }\end{array}$ & [42] & & & \\
\hline $\begin{array}{l}\text { Minimise reuse of } \\
\text { equipment (needles, } \\
\text { cookers, filters) }\end{array}$ & $\begin{array}{l}\text { Access to } \\
\text { sterile } \\
\text { equipment } \\
\text { not always } \\
\text { available }\end{array}$ & $\begin{array}{l}\text { Information } \\
\text { provision } \\
\text { about limiting } \\
\text { reuse of } \\
\text { equipment } \\
\text { (needles, } \\
\text { filters, } \\
\text { spoons) and } \\
\text { cleaning of } \\
\text { equipment if } \\
\text { it is reused } \\
\text { Provision of } \\
\text { street } \\
\text { injecting kits }\end{array}$ & [25] & & & \\
\hline Rotating sites & $\begin{array}{l}\text { Advice and } \\
\text { information } \\
\text { on how to } \\
\text { avoid venous } \\
\text { sclerosis, and } \\
\text { how to find } \\
\text { and safely } \\
\text { access less } \\
\text { visible veins, } \\
\text { was desired } \\
\text { by the } \\
\text { majority. }\end{array}$ & $\begin{array}{l}\text { Information } \\
\text { provision } \\
\text { about } \\
\text { rotating sites } \\
\text { Signposting } \\
\text { to healthcare } \\
\text { professionals } \\
\text { for support to } \\
\text { identify veins }\end{array}$ & [49] & & & \\
\hline
\end{tabular}

[Table 4. Behavioural analysis of REACT intervention using the COM-B model of behaviour and Behaviour Change Wheel] 


\section{(iv) Logic model}

The logic model provides the underpinning framework for the REACT intervention drawing together all the above. The logic model details the intervention aim and strategy, alongside the proposed intervention functions and behaviour change techniques. The process and intervention outcomes for a future intervention are also detailed (Table 5).

Table 5

REACT Logic model

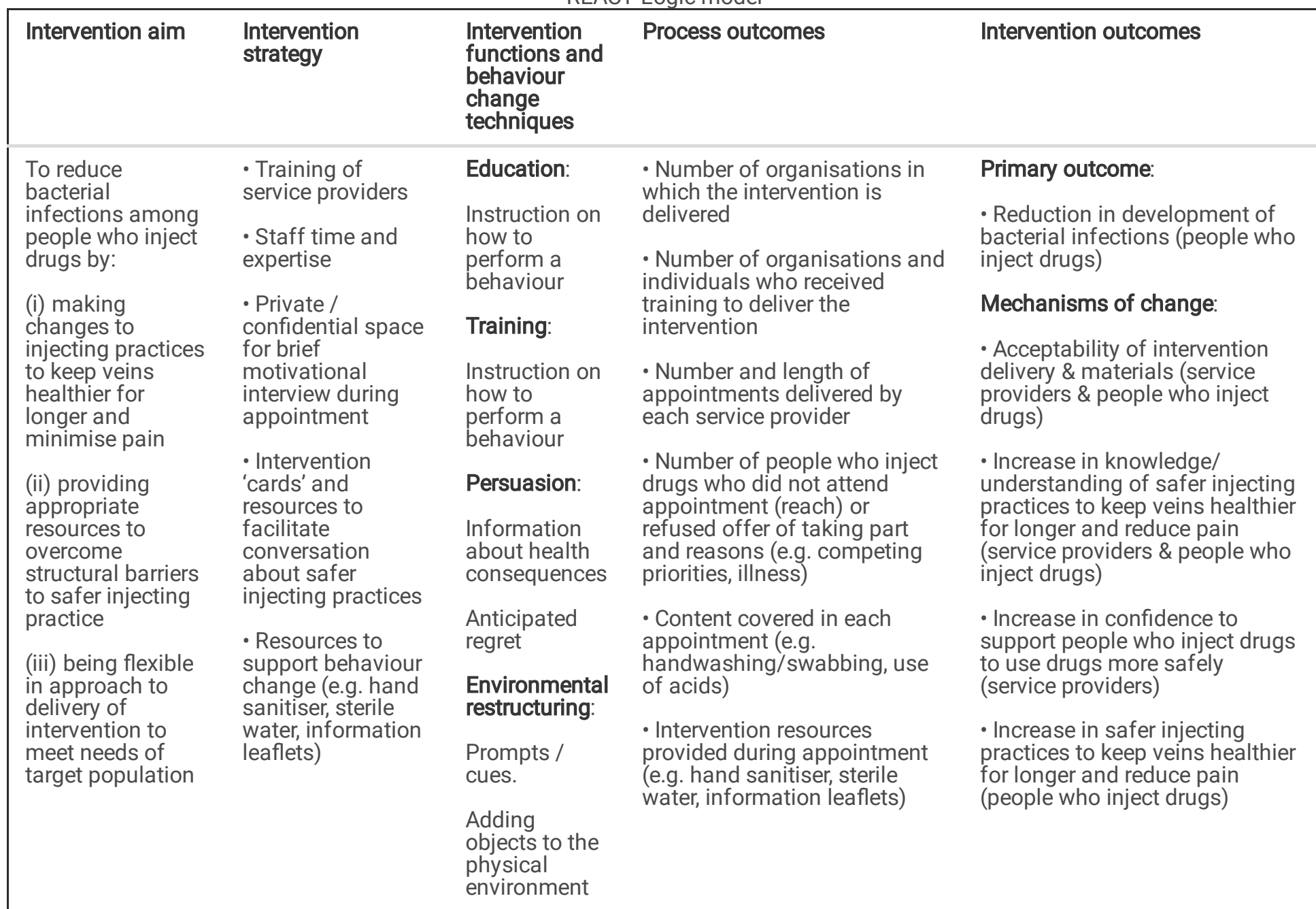

\section{CONTEXT}

National policies, initiatives and campaigns; local policies, initiatives and campaigns; impact of COVID-19 pandemic; social norms and values; professional norms and values; organisational policies and procedures, structural barriers to safer injecting.

People who inject drugs who access a range of services may have: previous experience of bacterial infections; difficulties prioritising safer injecting practice due to dependence; lack of opportunities to follow safer injecting practices (e.g. injecting outdoors); entrenched injecting practices; good knowledge of 'best practice'; experience of stigma and shame meaning

conversations about injecting behaviours are difficult. Attending to immediate priorities of people who inject drugs has potential.

\section{(v) Design and refinement of intervention materials}

The amended intervention was created, using a design brief, written content and suggested accompanying images, as a set of themed cards addressing risk factors for bacterial SSTI (see themes above). The designer selected a mid-century modern style and produced different versions of some cards for selection. Overall, PWID and key stakeholders provided positive feedback on the designs. Suggested alterations centred around using appropriate, clear language (e.g. 'part used amp' (ampoule) was changed to 
'part used sterile water') and clear imagery (e.g. ensuring an image of a citric acid sachet could not be confused with a transparent plastic bag used for drugs and using colour coding to indicate the gradient of risk with water options). The depiction of masculine hands was perceived to be potentially alienating for women who inject drugs. This was addressed in the next iteration of the designs by including female hands alongside male. The cards included a title page with the aim of the intervention, suggested ways of using the cards to facilitate a positive, non-judgemental conversation and an overview of the themes. The study manual encouraged service providers to tailor the intervention to the client's needs, the time available and the purpose of the conversation, emphasising that not everyone will necessarily benefit from every card. The accompanying intervention cards and study manual (see Additional files 1 and 2) and training course are available on the Exchange Supplies website [52]. The intervention training was supplemented with preexisting Exchange Supplies e-learning for NSP practitioners [53].

\section{Discussion}

We report the methods and PBA taken to develop a novel behavioural intervention. To optimise the intervention prototype and materials, we used an evidence-based and iterative approach, incorporating consultation and engagement with PWID, service providers, stakeholders and subject experts. There are few bespoke, individualised interventions that aim to reduce the risk of invasive SSTI, therefore this intervention addresses a gap in provision for PWID. Development of new interventions is especially important given the upward trend and increasing health burden from bacterial infections observed over recent years $[6,7]$.

The initial prototype intervention focused on targeting individual-level behaviour change around prevention and treatment of bacterial SSTI. Using evidence and the PBA to engage with target users and service providers, we identified that factors within the sociophysical environment increase the risk of injecting-related harm and need to be addressed, thus broadening the focus beyond an individualised approach. For example, as noted elsewhere, messages regarding handwashing prior to injection could be stigmatising and counterproductive to a client who is homeless [42]; while provision of sterile water and hand sanitiser may overcome barriers to handwashing. As such, intervention development acknowledged that both individual-level behavioural change and structural barriers to safer injecting practice needed to be addressed to maximise the likelihood of benefit.

In response to the feedback obtained, we also focused to a greater extent on vein care and primary prevention, rather than healthcare seeking behaviour and secondary prevention. Using the PBA strengthened understanding of the psychosocial context of those using the intervention and the behaviours to be addressed [27]. The beneficial impact of this co-production, involvement and iterative prototyping for public health interventions has been demonstrated in another study in this field [54]. Our study strengthens this evidence base and provides a blueprint for the process.

The intervention we describe here shares features with previous interventions [17-20] via a focus on hand hygiene, education and enablement, and tailored risk reduction but includes a strong focus on collaborative intervention development. Assessing the acceptability and feasibility of the REACT intervention is the focus of an ongoing pilot study.

\section{Strengths and limitations}

Strengths of our approach to intervention development include the use of an established research methodology, the PBA [29], and the collaboration with PWID, service providers, and key stakeholders including multi-disciplinary academics, harm reduction practitioners, public health professionals and suppliers of harm reduction materials using an iterative approach throughout to determine the design of the REACT intervention. To ensure we developed an intervention that was underpinned by theory, we used constructs from the COM-B model and Behaviour Change Wheel [30] to define the intervention processes and components and behaviour change techniques [31] to be targeted.

However, the views expressed by contributors may not be generalisable to PWID in different geographical locations and there may be different views among PWID at different stages of their injecting history. Furthermore, DH and CL are specialist harm reduction experts experienced at building a rapport with PWID therefore it is important to understand the acceptability and feasibility to deliver the intervention outside specialist drug services by service providers who may be less experienced at having these types of conversation. Structural barriers to lower-risk injection remain and we acknowledge that although addressed as far as possible by this intervention, there are a range of additional issues that this intervention cannot address (e.g. lack of safe spaces to inject in). Lastly, development of the intervention was time intensive, involving multiple stakeholders, and we cannot yet comment on the resulting acceptability or feasibility of the intervention when delivered in practice. 


\section{Conclusions}

Using the PBA, we have gained insight into the psychosocial context of the target population and optimal design features by using an iterative approach to intervention development and integrating feedback at each stage of intervention development. This allowed us to adapt features of the intervention in anticipation of likely intervention usage to increase persuasiveness and feasibility to deliver the intervention in practice. Future work will be piloting the intervention to establish the feasibility and acceptability of the intervention from the perspectives of service providers and PWID and the impact of the intervention on attitudes and motivations to change injection practice.

\section{Abbreviations}

COM-B: Capacity Opportunity Motivation - Behaviour

DiPS: Design in Public Sector

iGAS: invasive Group A Streptococci

MRSA: methicillin-resistant Staphylococcus aureus

NSP: Needle and Syringe Programmes

OST: Opiate Substitute Therapy

PBA: Person-Based Approach

PWID: People Who Inject Drugs

REACT: REducing bACTerial infections

SSTI: Skin and Soft Tissue Infections

UK: United Kingdom

USA: United States of America

\section{Declarations}

\section{Ethics approval and consent to participate}

Research approvals from the University of Bristol's Faculty of Health Sciences Research Ethics Committee (reference: 108304) were obtained to undertake the study overall (which included a pilot phase and interviews with participants and service providers). Consultations that informed intervention development were classified as Patient and Public Involvement therefore the University of Bristol's Faculty of Health Sciences Research Ethics Committee has waived consent for this study. However, good research practice was followed throughout. Prior to the consultation, the researcher explained the purpose and procedures of the consultation, and explicitly asking the respondent if they understood everything, and wanted to contribute. They were also informed they stop the consultation at any time. All methods were carried out in accordance with relevant guidelines and regulations.

\section{Consent for publication}

Not applicable.

\section{Availability of data and materials}

All data generated or analysed during this study are included in this published article. 


\section{Competing interests}

None declared.

\section{Funding}

This work was supported by the University of Bristol RED fund, ESRC Impact Acceleration Award and Bristol Health Partners Drug and Alcohol Health Integration Team (HIT).

\section{Authors' contributions}

MT, DM, GM, JK developed the concept for this study (alongside other colleagues) and contributed to study design; HF, DH and CL

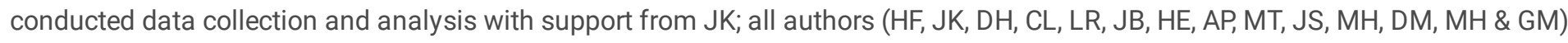
provided stakeholder feedback and contributed to interpretation of results. HF prepared the first draft of the manuscript; JK and GM contributed to manuscript development. All (HF, JK, DH, CL, LR, JB, HE, AP, MT, JS, MH, DM, MH \& GM) authors read and contributed to the final version.

\section{Acknowledgements}

JK is partly funded by National Institute for Health Research Applied Research Collaboration West (NIHR ARC West) and NIHR Health Protection Research Unit in Behavioural Science and Evaluation.

HF was supported by the University of Bristol RED fund.

GM was supported by the South West Public Health Training Scheme and Bristol, North Somerset and South Gloucestershire Clinical Commissioning Group Research Capability Funding.

DH and CL's time on the project was supported by the Bristol Health Partner's Drug and Alcohol HIT.

This study was supported by the National Institute for Health Research (NIHR) Health Protection Research Unit (HPRU) in Behavioural Science and Evaluation at the University of Bristol, in partnership with Public Health England (PHE). The views expressed are those of the author and not necessarily those of the NIHR, the Department of Health and Social Care, or PHE.

We would like to thank service users and staff at Bristol Drugs Project for their feedback on the prototype intervention and the clients, stakeholders, professionals and service provider organisations who provided feedback and insights that contributed to this work.

\section{References}

1. Degenhardt, L., et al., Global patterns of opioid use and dependence: harms to populations, interventions, and future action. Lancet, 2019. 394(10208): p. 1560-1579.

2. Del Giudice, P., Cutaneous complications of intravenous drug abuse. British Journal of Dermatology, 2004. 150(1): p. 1-10.

3. Public Health England. Wound aware: a resource for commissioners and providers of drug services. 2021. Available from:https://www.gov.uk/government/publications/wound-aware-a-resource-for-drug-services/wound-aware-a-resource-forcommissioners-and-providers-of-drug-services.

4. Croxford, S., et al., Unlinked Anonymous Monitoring (UAM) Survey of HIV and viral hepatitis among PWID: 2021 report Health Protection Report 2021.

5. Wright, T., et al., Prevalence and severity of abscesses and cellulitis, and their associations with other health outcomes, in a community-based study of people who inject drugs in London, UK. PLOS ONE, 2020. 15(7): p. e0235350.

6. Public Health England, Shooting Up: infections among people who inject drugs in the UK, 2019. An update, December 2020. 2020, Public Health England: UK. . 
7. Collier, M., M. Doshani, and A. Asher, Using Population Based Hospitalization Data to Monitor Increases in Conditions Causing Morbidity Among Persons Who Inject Drugs. J Community Health, 2018. 43(3): p. 598-603.

8. Valenciano, S., et al., Invasive Group A Streptococcal Infections Among People Who Inject Drugs and People Experiencing Homelessness in the United States, 2010-2017. Clin Infect Dis, 2020.

9. Marks, M., et al., Needles and the damage done: reasons for admission and financial costs associated with injecting drug use in a Central London Teaching Hospital. J Infect, 2013. 66(1): p. 95-102.

10. Baltes, A., et al., Predictors of skin and soft tissue infections among sample of rural residents who inject drugs. Harm Reduct $J$, 2020. 17(1): p. 96.

11. Dahlman, D., et al., Behavioral characteristics and injection practices associated with skin and soft tissue infections among people who inject drugs: A community-based observational study. Subst Abus, 2017. 38(1): p. 105-112.

12. Moradi-Joo, M., et al., Prevalence of skin and soft tissue infections and its related high-risk behaviors among people who inject drugs: A systematic review and meta-analysis. Journal of Substance Use, 2019. 24(4): p. 350-360.

13. Hope, V., et al., Healthcare seeking and hospital admissions by people who inject drugs in response to symptoms of injection site infections or injuries in three urban areas of England. Epidemiology and Infection, 2015. 143(1): p. 120-131.

14. Harris, M., Normalised pain and severe health care delay among people who inject drugs in London: Adapting cultural safety principles to promote care. Social Science \& Medicine, 2020. 260: p. 113183.

15. Neale, J., C. Tompkins, and L. Sheard, Barriers to accessing generic health and social care services: a qualitative study of injecting drug users. Health Soc Care Community, 2008. 16(2): p. 147-54.

16. Bradbury, M. and D. Lewer, Role of community drug and alcohol services in physical healthcare for people who use illicit opioids: a qualitative study of clinical staff in the UK. BMJ Open, 2021. 11(7): p. e046577.

17. Roux, P., et al., Innovative community-based educational face-to-face intervention to reduce HIV, hepatitis $C$ virus and other bloodborne infectious risks in difficult-to-reach people who inject drugs: results from the ANRS-AERLI intervention study. Addiction, 2016. 111(1): p. 94-106.

18. Mezaache, S., et al., Changes in supervised drug-injecting practices following a community-based educational intervention: A longitudinal analysis. Drug and Alcohol Dependence, 2018. 192: p. 1-7.

19. Mezaache, S., et al., A two-component intervention to improve hand hygiene practices and promote alcohol-based hand rub use among people who inject drugs: a mixed-methods evaluation. BMC Infect Dis, 2021. 21(1): p. 211.

20. Phillips, K., et al., A randomized controlled trial of a brief behavioral intervention to reduce skin and soft tissue infections among people who inject drugs. Drug Alcohol Depend, 2021. 221: p. 108646.

21. Brothers, T., et al., Social and structural determinants of injecting-related bacterial and fungal infections among people who inject drugs: protocol for a mixed studies systematic review. BMJ Open, 2021. 11(8): p. e049924.

22. Bristol City Council and Bristol, North Somerset, South Gloucestershire Clinical Commissining Group. JSNA Health and Wellbeing Profile 2020/21. Substance Misuse. 2021.

23. Packer, S., et al., Clonal expansion of community-associated meticillin-resistant Staphylococcus aureus (MRSA) in people who inject drugs (PWID): prevalence, risk factors and molecular epidemiology, Bristol, United Kingdom, 2012 to 2017. Euro Surveill, 2019. 24(13).

24. Design Council. What is the framework for innovation? Design Council's evolved Double Diamond. 2021 [cited 202123 July].

25. Dunleavy, K., et al., The experiences of people who inject drugs of skin and soft tissue infections and harm reduction: A qualitative study. Int J Drug Policy, 2019. 65: p. 65-72.

26. DiPS, Reducing Harm from Invasive Bacterial Infections Among People Who Inject Drugs in and Around Bristol. Report of a Design Council and Local Government Association 'Design in the Public Sector' Programme., P.i. process, Editor. 2019.

27. Yardley, L., et al., The person-based approach to enhancing the acceptability and feasibility of interventions. Pilot and Feasibility Studies, 2015. 1(1): p. 37.

28. Bradbury, K., et al., Developing Digital Interventions: A Methodological Guide. Evidence-Based Complementary and Alternative Medicine, 2014. 2014: p. 561320.

29. Yardley, L., et al., The Person-Based Approach to Intervention Development: Application to Digital Health-Related Behavior Change Interventions. J Med Internet Res, 2015. 17(1): p. e30.

Page 23/25 
30. Michie, S., M. van Stralen, and R. West, The behaviour change wheel: A new method for characterising and designing behaviour change interventions. Implementation Science, 2011. 6(1): p. 42.

31. Michie, S., et al., From theory to intervention: mapping theoretically derived behavioural determinants to behaviour change techniques. J Applied psychology, 2008. 57(4): p. 660-680.

32. Skivington, K., et al., A new framework for developing and evaluating complex interventions: update of Medical Research Council guidance. British Medical Journal, 2021. 374.

33. Larney, S., et al., A systematic review of injecting-related injury and disease among people who inject drugs. Drug Alcohol Depend, 2017. 171: p. 39-49.

34. Vlahov, D., et al., Bacterial infections and skin cleaning prior to injection among intravenous drug users. Public Health Rep, 1992. 107(5): p. 595-8.

35. Murphy, E., et al., Risk factors for skin and soft-tissue abscesses among injection drug users: a case-control study. Clin Infect Dis, 2001. 33(1): p. 35-40.

36. Dwyer, R., et al., Prevalences and correlates of non-viral injecting-related injuries and diseases in a convenience sample of Australian injecting drug users. Drug Alcohol Depend, 2009. 100(1-2): p. 9-16.

37. Hope, V., et al., Frequency, factors and costs associated with injection site infections: findings from a national multi-site survey of injecting drug users in England. BMC Infect Dis, 2008. 8: p. 120.

38. Stein, M., et al., Skin-cleaning among hospitalized people who inject drugs: a randomized controlled trial. Addiction, 2020.

39. Ciccarone, D. and M. Harris, Fire in the vein: Heroin acidity and its proximal effect on users' health. The International journal on drug policy, 2015. 26(11): p. 1103-1110.

40. Harris, M., The 'do-it-yourself'New Zealand injecting scene: Implications for harm reduction. International Journal of Drug Policy, 2013. 24(4): p. 281-283.

41. Harris, M., et al., Injecting-related health harms and overuse of acidifiers among people who inject heroin and crack cocaine in London: a mixed-methods study. Harm Reduction Journal, 2019. 16(1): p. 60.

42. Harris, M., et al., Navigating environmental constraints to injection preparation: the use of saliva and other alternatives to sterile water among unstably housed PWID in London. Harm Reduction Journal, 2020. 17(1): p. 24.

43. Lloyd-Smith, E., et al., Risk factors for developing a cutaneous injection-related infection among injection drug users: a cohort study. BMC public health, 2008. 8: p. 405-405.

44. Hope, V., et al., The extent of injection site infection in injecting drug users: findings from a national surveillance study. Epidemiology and Infection, 2010. 138(10): p. 1510-1518.

45. Darke, S., J. Ross, and S. Kaye, Physical injecting sites among injecting drug users in Sydney, Australia. Drug Alcohol Depend, 2001. 62(1): p. 77-82.

46. Rance, J., et al., Practices of partnership: Negotiated safety among couples who inject drugs. Health (London), 2018. 22(1): p. 319.

47. Wright, N., C. Tompkins, and L. Jones, Exploring risk perception and behaviour of homeless injecting drug users diagnosed with hepatitis C. Health Soc Care Community, 2005. 13(1): p. 75-83.

48. Hope, V., et al., Not in the vein: 'missed hits', subcutaneous and intramuscular injections and associated harms among people who inject psychoactive drugs in Bristol, United Kingdom. Int J Drug Policy, 2016. 28: p. 83-90.

49. Harris, M. and T. Rhodes, Venous access and care: harnessing pragmatics in harm reduction for people who inject drugs. Addiction, 2012. 107(6): p. 1090-1096.

50. McNeil, R. and W. Small, 'Safer environment interventions': a qualitative synthesis of the experiences and perceptions of people who inject drugs. Soc Sci Med, 2014. 106: p. 151-8.

51. The Exchange Supplies website: Injecting Tips \#1: Bacterial infections 2021 https://www.exchangesupplies.org/shopdisp_Injecting_tips_leaflet_bacterial_infections_colour.php. Accessed: 24/01/22

52. The Exchange Supplies website:https://training.exchangesupplies.org/bdpreact-stage_1. Accessed: $24 / 01 / 22$.

53. The Exchange Supplies website: Exchange Training 2021; Website:https://training.exchangesupplies.org/. Accessed: $24 / 01 / 22$

54. Hussey, D., et al., Co-design of harm reduction materials for people who inject drugs to implement research findings. Harm Reduct J, 2019. 16(1): p. 36.

Page 24/25 
55. Treloar, C., et al., Broadening discussions of "safe" in hepatitis C prevention: a close-up of swabbing in an analysis of video recordings of injecting practice. Int J Drug Policy, 2008. 19(1): p. 59-65.

\section{Figures}

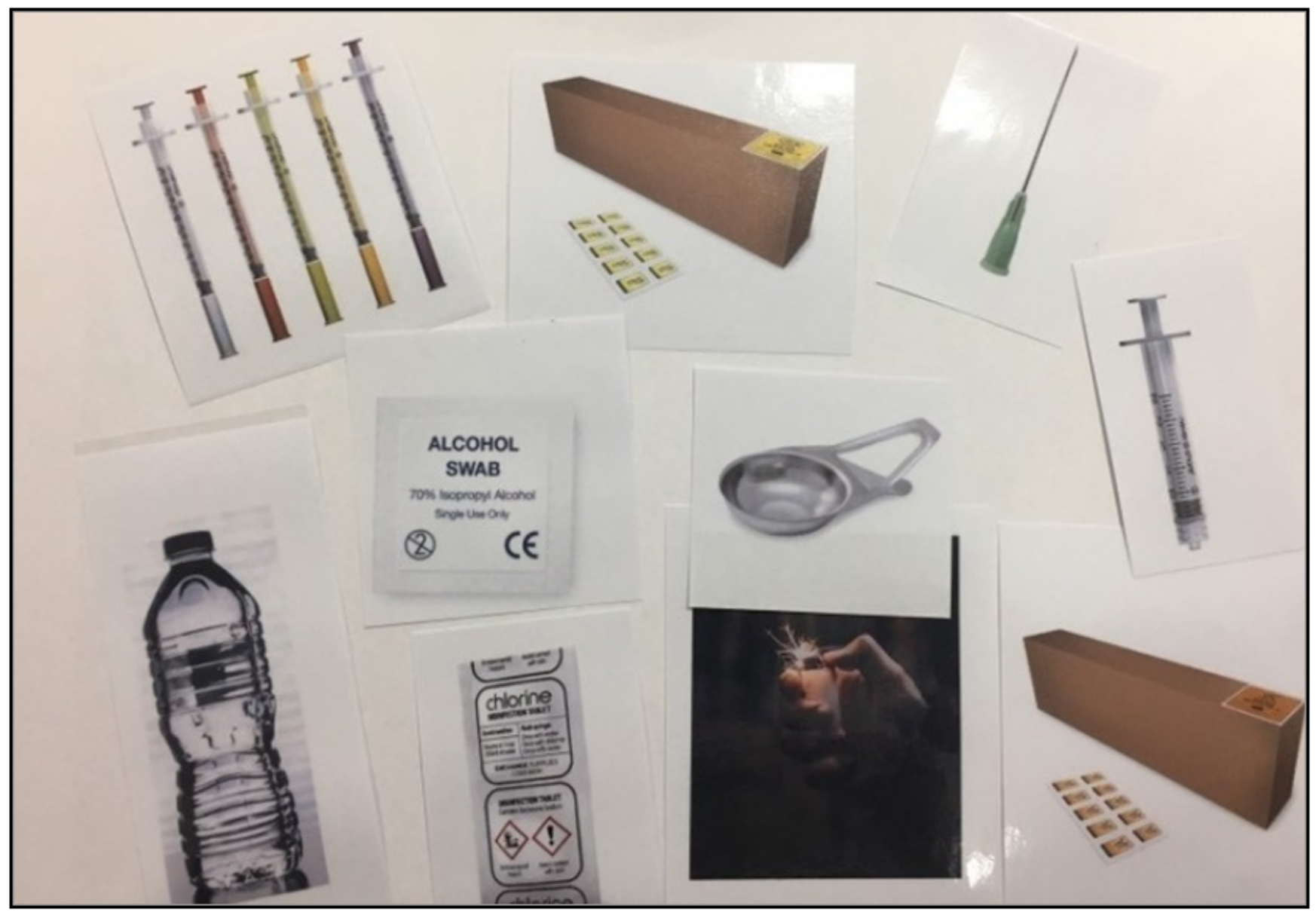

\section{Figure 1}

Prototype intervention materials

\section{Supplementary Files}

This is a list of supplementary files associated with this preprint. Click to download.

- Additionalfile1 Interventioncards.pdf

- Additionalfile2Studymanual.pdf 